\title{
Subclavian oblique-axis catheterization technique
}

\author{
Alessandro De Cassai ${ }^{*}$ (D) and Helmut Galligioni \\ See related review by Saugel et al., https://ccforum.biomedcentral.com/articles/10.1186/s13054-017-1814-y
}

We read with interest the work by Saugel et al. [1] about ultrasound-guided central venous catheter placement.

In their work the authors accurately describe "in-plane" and "out of plane" techniques for central venous catheter access. However, they describe only briefly the oblique-axis technique and for this approach only articles about internal venous jugular catheterization are cited $[2,3]$ and nothing in the literature about the oblique axis for subclavian access could be found.

In our experience we make regular use of the obliqueaxis technique for placing subclavian catheters with a high success rate and a low rate of complications. An important aspect for a successful procedure is patient positioning; in fact, the best visualization of the subclavian vein and artery is, in our experience, possible with a $90^{\circ}$ abduction of the arm. After aseptic preparation the ultrasound probe is covered with a protective plastic sheath. Ultrasound inspection is started laterally near the axilla to identify the axillary vein and artery in a classic "out of plane" view, after which the vessels are followed until the joint point of the axillary vein with the cephalic vein (Fig. 1): this is the anatomic subclavian starting point. After a $45^{\circ}$ rotation of the probe an oblique view is then possible (Fig. 2). It is an easy method with great advantages in comparison with "in-plane" and "out of plane" views because it permits both visualization of the tip of the needle and important anatomical structures such as the artery or vein (both with an oval shape due to projection) and, moreover, sliding of the lung.

\footnotetext{
*Correspondence: alessandro.decassai@gmail.com

Emergency Department, Azienda Ospedaliera di Padova, Padua, Italy
}
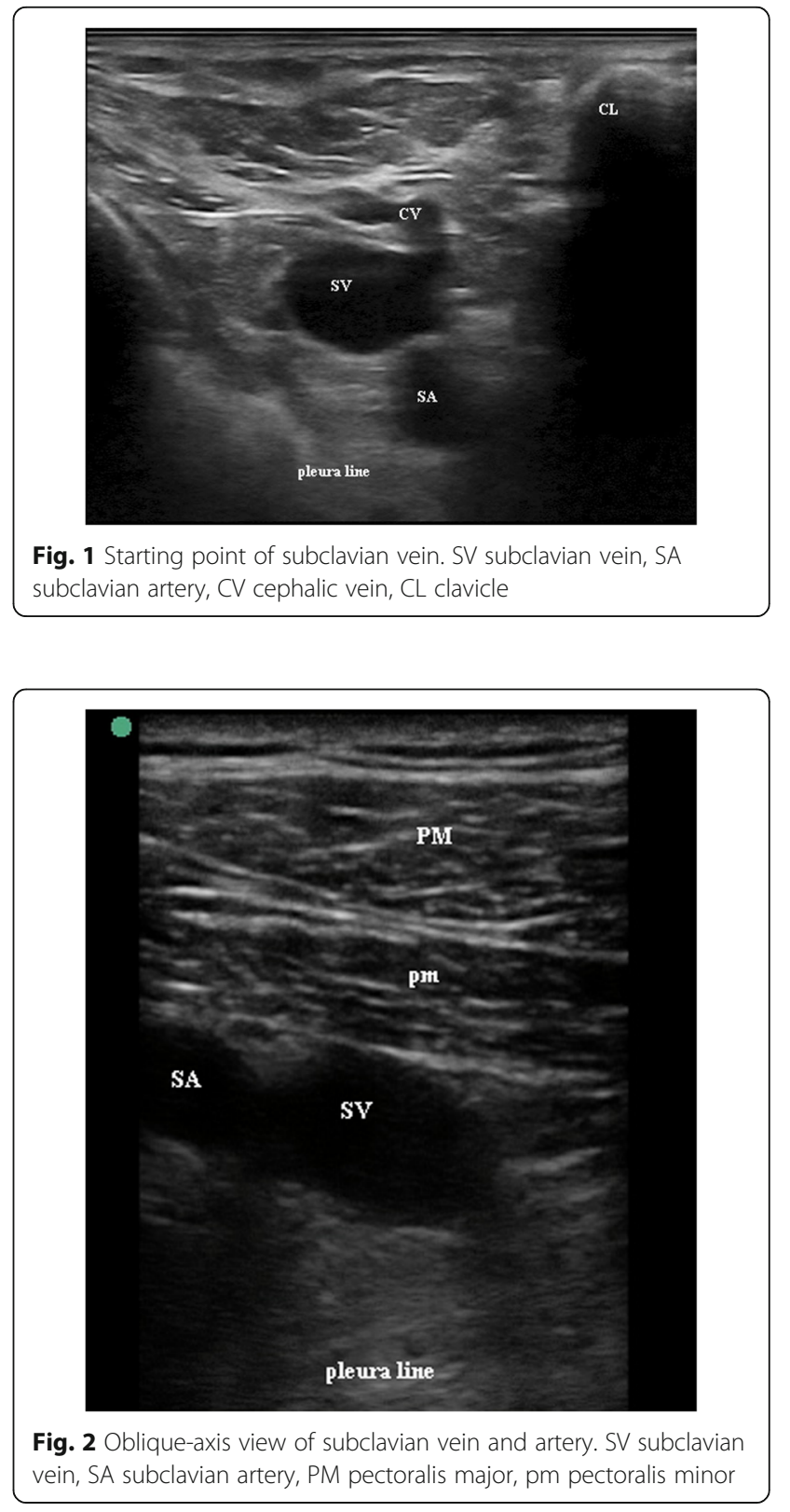

Fig. 2 Oblique-axis view of subclavian vein and artery. SV subclavian vein, SA subclavian artery, PM pectoralis major, pm pectoralis minor 


\section{Acknowledgements}

None.

\section{Funding}

None.

Availability of data and materials

Not applicable.

\section{Authors' contributions}

ADC was responsible for conceptualization, writing and the original draft of the manuscript. HG was responsible for writing, review and editing of the manuscript. Both authors read and approved the final manuscript.

Ethics approval and consent to participate

Not applicable.

\section{Consent for publication}

Not applicable.

\section{Competing interests}

The authors declare that they have no competing interests.

\section{Publisher's Note}

Springer Nature remains neutral with regard to jurisdictional claims in published maps and institutional affiliations.

Received: 20 November 2017 Accepted: 4 December 2017

Published online: 27 December 2017

\section{References}

1. Saugel B, Scheeren TWL, Teboul J-L. Ultrasound-guided central venous catheter placement: a structured review and recommendations for clinical practice. Crit Care. 2017;21:225. https://doi.org/10.1186/s13054-017-1814-y.

2. Phelan $M$, Hagerty $D$. The oblique view: an alternative approach for ultrasound-guided central line placement. J Emerg Med. 2009;37:403-8. https://doi.org/10.1016/j.jemermed.2008.02.061.

3. Wilson JG, Berona KM, Stein JC, Wang R. Oblique-axis vs. short-axis view in ultrasound-guided central venous catheterization. J Emerg Med. 2014;47:45-50 https://doi.org/10.1016/j.jemermed.2013.11.080. 